\title{
Is KANT'S TRANSCENDENTAL DEDUCTION OF The Categories Fit for Purpose?
}

\author{
Anil Gomes \\ Birkbeck College, London \\ Forthcoming, Kantian Review [accepted 2010]
}

\begin{abstract}
James Van Cleve has argued that Kant's Transcendental Deduction of the categories shows, at most, that we must apply the categories to experience. And this falls short of Kant's aim, which is to show that they must so apply. In this discussion I argue that once we have noted the differences between the first and second editions of the Deduction, this objection is less telling. But Van Cleve's objection can help illuminate the structure of the B Deduction, and it suggests an interesting reason why the rewriting might have been thought necessary.
\end{abstract}

\section{Introduction}

Is Kant's transcendental deduction of the categories fit for purpose? By this I mean: is it structured so as to meet the objectives which it aims to fulfil? James Van Cleve has recently argued that it is not. ${ }^{1}$ According to Van Cleve, Kant's aim in the Transcendental Deduction is to show 'that the concepts of substance and causation and the other a priori concepts on [Kant's] list of twelve are exemplified in the world we experience' (p.73). This objective will be met if it can be shown that the categories are actually exemplified in experience. But, Van Cleve argues, the most that the Transcendental Deduction shows is that we must apply the categories to

${ }^{1}$ (Van Cleve 1999, ch. 7). All page references to this work. 
experience. And that falls short of showing that they must be so exemplified. Thus is Kant's deduction unfit for purpose.

Van Cleve takes this to be a fundamental criticism of the Deduction, and one which 'has not received the attention it deserves' (p.89). I propose to remedy that deficit in this discussion. In what follows I will set out Van Cleve's objection and suggest that it has some force against the first edition version of the Transcendental Deduction. But Kant famously rewrote the Transcendental Deduction almost in its entirety for the second edition of the Critique. $^{2}$ Once the differences between the $\mathrm{A}$ and $\mathrm{B}$ versions of the Deduction have been noted, the objection is less telling. Nevertheless, attention to this objection can help illuminate the structure of the B Deduction, and it suggests an interesting reason for why the rewriting might have been thought necessary.

In what follows I will not be concerned to assess the truth of the various claims made in the Deduction, nor will I discuss Van Cleve's extremely clear and interesting objections to the premises he identifies. My concern is simply with the general structure of the argument and Van Cleve's contention that this structure does not lead where Kant wished to go. This is what I wish to challenge.

\section{Van Cleve's Objection}

Let us accept Van Cleve's suggestion that the aim of the Transcendental Deduction is to show that the categories are instantiated in experience. How does Kant's deduction aim to meet this task? As Van Cleve interprets the argument, it involves three premises:

The Unity Premise: All representations of which I am conscious have unity of apperception.

The Synthesis Premise: Representations can have such unity only if they have been synthesised.

The Category Premise: Synthesis requires the application of Kant's categories.

Conclusion: The categories apply to all representations of which I am conscious. (p.79)

2 (Kant 1998). All references to the first Critique are in the standard 'A' and 'B' notation, and refer to the Guyer and Wood translation. I have underlined text that is given as bold in their translation. 
This can be summarised as a chain of implications moving from consciousness to the categories: consciousness implies unity of apperception; unity of apperception implies synthesis; synthesis implies the categories. We move from a claim about the nature of consciousness to a conclusion about the application of the categories.

Is Van Cleve's interpretation adequate? In structuring the Deduction as a move from consciousness to categories, Van Cleve's reconstruction follows the final 'systematic' exposition of the A Deduction. ${ }^{3}$ Kant's starting point in this final exposition is the transcendental unity of apperception: the principle that 'we are conscious a priori of the thoroughgoing identity of ourselves with regard to all representations that can ever belong to our cognition, as a necessary condition of the possibility of all representations' (A116). This principle is intended to capture the thought that it is a feature of self-consciousness that I can, at least potentially, recognise all my representations as belonging to me: my representations are unified in that it is possible to relate them all to my consciousness. All representations 'have a necessary relation to a possible empirical consciousness for if they did not have this, and if it were entirely impossible to become conscious of them, that would be as much as to say that they did not exist at all' (A117). Hence Van Cleve's unity premise: all representations of which I am conscious are subject to the unity of apperception.

Kant's next question in the A Deduction concerns the status of this unity: what does the unity of apperception consist in? He argues that the unity of the manifold of representations in a subject is not an analytic unity in virtue of the content of the representations, but is instead a synthetic unity: 'the unity of the manifold in a subject is synthetic; pure synthesis therefore yields a principle of the synthetic unity of the manifold in all possible intuition' (A116-7). This synthetic unity is only possible if the representations are subject to an a priori synthesis (A118). Hence the synthesis premise: representations can have such a unity only if they have been synthesised. This is stressed in the preparatory exposition where Kant highlights that such an a priori synthesis must take place according to certain a priori rules (A108).

\footnotetext{
3 (A115-30). A preliminary exposition takes place at (A98-114). For discussion of the differences between the preliminary and final expositions, see (Guyer 1992, pp.136-146).
} 
Thus far Kant has argued that the synthesis of the manifold of representations necessary for the unity of apperception must take place according to certain a priori rules. What are these a priori rules? For Kant, these rules are simply the categories: synthesis requires application of the categories. This is Van Cleve's category premise, and as he makes clear (p.88), it rests in part on the results of the Metaphysical Deduction of the categories in which Kant argues that synthesis requires judging and that judging requires the use of the categories. ${ }^{4}$ But Kant also draws attention to the fact that the source of all combination is the faculty of understanding, and thus that the a priori rules necessary for the transcendental unity of apperception will be the basic a priori rules of pure understanding (A119). Since, for Kant, concepts function as rules, the basic a priori rules of the understanding are the pure concepts of the understanding, namely the categories.

In summary, then, the A Deduction proceeds as follows: all representations are subject to the transcendental unity of apperception. This unity is synthetic. Such a synthetic unity requires an a priori synthesis of the manifold according to a priori rules. These rules are the categories. Van Cleve's reconstruction is a fair one. ${ }^{5}$

How should we evaluate this argument? Van Cleve has much to say about the individual premises, but my interest here is his identification of a wider structural problem with the argument. Even if Kant could show that synthesis involves judging, and that judging involves the application of the categories, he writes:

...this would not be enough for his purposes. For that result in conjunction with the rest of the Transcendental Deduction would yield no conclusion stronger than this: all my representations are connected in judgements that use Kant's categories. But Kant wants to show that the categories are objectively valid - that they actually apply to objects of experience. (p.89)

And this, Van Cleve argues, simply does not follow.

What is the problem? According to Van Cleve's reconstruction, the conclusion of the Transcendental Deduction has it that we must apply the

\footnotetext{
4 (A66-84/ B91-116)

5 (Guyer 1992) provides readings of the A Deduction in this vein.
} 
categories to our representations in order that they be subject to the unity of apperception. What this means is that the manifold of intuition must be bound up and synthesised in accordance with the categories in order that they display the unity necessary to ground transcendental apperception. This is a claim about our application of the categories: we must apply the categories to experience in order to explain the unity of consciousness. But it doesn't follow from this, Van Cleve claims, that the categories are actually instantiated in experience. Why not? Because our application of the categories could be mistaken. Perhaps our application of the categories in experience is always mistaken, and there is nothing which corresponds to the way in which we have synthesised the manifold. From the fact that we must apply the categories to our representations, nothing follows about the objective validity of the categories themselves.

Consider two representation of which I am conscious. According to the unity premise these representations stand under the unity of apperception, which is to say that I can recognise them as belonging to me. These representations do not stand under the unity of apperception in virtue of any shared content; rather their unity is a synthetic unity. That is, they must have been synthesised in order to stand under the unity of apperception. Synthesis is a process which involves judging, and judging takes place according to certain logical forms, that is, according to certain a priori rules. These a priori rules are the categories. So in order for these representations to count as being conscious for me, I must have synthesised them in accordance with the categories. This is a claim about my application of the categories: in synthesising these representations, I must employ the categories. It does not follow that the categories are exemplified in experience unless we can be assured that my employment of the categories was accurate. And nothing in the argument so far provides this guarantee.

According to this objection, the Transcendental Deduction is not built to meet the objectives with which it was commissioned. Van Cleve writes:

I fear some may have overlooked this obvious point because of the easy verbal slide from 'we must apply the categories' to 'the categories must apply'. One may slip without noticing from one to the other, but between the two there is no small distance. It is the distance between our using a category and its being instantiated, or between making a judgement and it being true.' (p.89). 
The conclusion of the Deduction shows only that we must apply the categories. And this is a far cry from showing that the categories must apply.

I think Van Cleve's objection is an interesting one. Certainly it identifies a structural weakness in his reconstructed version of the Deduction, and to the extent that his reconstruction is a fair interpretation of the first edition version of the Deduction - as I have suggested that it is - then it has some force. But Kant rewrote the Transcendental Deduction in its entirety for the second edition of the Critique, and though he claimed that the rewrite concerned only 'revisions of the mode of presentation' and not the 'propositions themselves and their grounds of proof (Bxxxvii-xxxviii), many have found the changes more substantial. In the rest of this paper, I will contrast the argument presented in the A Deduction with the argument presented in the B Deduction, and suggest that Van Cleve's objection is less telling against the second edition version. Kant understood - or at least, came to understand - the distinction between showing that we must apply the categories and showing that the categories must apply, and his argument aims at the stronger conclusion. Consideration of Van Cleve's objection can highlight an important structural feature of the B Deduction.

\section{The B Deduction (\$\$15-19)}

How does the B Deduction compare to the A Deduction? As has been well documented, the B Deduction proof consists of two separate stages, $\$ \$ 15$ 19 and $\$ \$ 22-26 .{ }^{6}$ In this section I will set out an overview of the first stage of the B Deduction, and compare its structure with that of the A Deduction. Once again, my sole concern is to present a structural overview of the argument in order to see how it relates to Van Cleve's objection.

Whereas the final systematic exposition of the A Deduction begins with the unity of consciousness, the B Deduction begins by asking what is necessary in order for a manifold of representations to be combined. As such it follows the recasting of the A Deduction 'from beneath' at A120. In section 15 the $B$ Deduction begins with the claim that 'the combination of the manifold in general can never come to us through the senses' (B129), and must therefore be united in the understanding. The threefold 
synthesis necessary to combine the manifold which is given so much space in the A Deduction is passed over briefly (B130); instead the emphasis is on the fact that only the understanding can combine the manifold of representations for 'among all representations combination is the only one that is not given through objects but can be executed only by the subject itself (B130). ${ }^{7}$

Section 16 asks what unity would make such a combination possible, and answers (in the title of the section) the original-synthetic unity of apperception. This reiterates the claims made in the A Deduction: 'the I think must be able to accompany all my representations' (B131). Once again it is stressed that the nature of this unity is synthetic, though this time this follows equally from the considerations of section 15: the manifold can be synthesised only if my representations involve a synthetic unity, such a unity is the original-synthetic unity of apperception.

Having considered the structure of the A Deduction, we might now expect Kant to argue that such a synthesis must take place according to a priori rules. But after a discussion about the nature of objects $(\$ 17)$, Kant brings in considerations about the nature of judgement which can seem completely new (\$19). He now argues that the understanding brings representations under the unity of apperception by means of judging, for 'a judgement is nothing other than the way to bring given cognitions to the objective unity of apperception' (B141). And the act of judging involves application of the categories. In fact this step simply makes explicit the appeal to the Metaphysical Deduction relied upon in the A Deduction, and it allows Kant to conclude in section 20: 'the manifold in a given intuition also necessarily stands under categories' (B143).

The argument thus far is as follows: the manifold can be synthesised only if it contains a synthetic unity. This unity is the original unity of apperception. Bringing representations under the unity of apperception, i.e., synthesising them, involves making judgments, and judgements must employ the categories. Although this argument starts 'from beneath', as does the recasting of the A Deduction at A120, we can see the similarity to

\footnotetext{
${ }^{7}$ Kant adds at the end of section 15 a surprising claim about combination presupposing a unity of the manifold which 'precedes all combination of concepts a priori' (B131). Many commentators have found this passage troubling, and pass over it in reconstructions of the B Deduction's argument (see, e.g., (Guyer 1992, pp.149-150)). I discuss this passage in section 4 below.
} 
the argument of the A Deduction expounded above. Only under the synthetic unity of apperception, which is a faculty of the pure understanding, can the manifold be combined (synthesised). Synthesis under the pure understanding involves judging which itself takes place according to the categories. There are clearly differences of detail between the two arguments, most notably the surfacing of the considerations about judging in the B Deduction and the contraction of the story about how exactly synthesis works. But, in broad brushstrokes, the arguments follow the same pattern.

Given these structural parallels, the conclusion of section 20 of the B Deduction seems equally open to Van Cleve's objection As Kant reiterates in section 20, the argument so far has shown that the manifold given in sensible intuition needs to be synthesised in accordance with the logical functions for judgement, i.e., the categories. And this synthesis involves making judgements which employ the categories, a process which is necessary in order for the manifold of intuition to show the unity necessary for transcendental apperception. But, once again, this conclusion concerns only our application of the categories: in order for the manifold to be unified under the synthetic unity of apperception, we must synthesise it by making judgements which employ the categories. But this is not yet to show that the categories must apply to the objects of experience, for such an application could be inapt. The first step of the B Deduction $(\$ \$ 15-19)$ parallels the final exposition of the A Deduction, and seems correspondingly vulnerable to Van Cleve's challenge.

\section{The B Deduction (\$\$20-26)}

However $\$ \$ 15-19$ comprise only the first part of the B Deduction proof; Kant explicitly states that the later sections are needed to complete the proof. 'In the above proposition, therefore, the beginning of a deduction of the pure concepts of the understanding has been made...', 'In the sequel $(\$ 26) \ldots$ the aim of the deduction will be fully attained' (B144-5). This raises the following question: if $\$ \$ 15-19$ roughly correlate to the $A$ Deduction, as alleged above, then what does the second stage of the proof in the B Deduction add that was not in the A Deduction? Consideration of the relation between the two parts of the B Deduction can help provide an answer to Van Cleve's objection. 
As Dieter Henrich has stressed, Kant's emphasis on the two-part structure places an exegetical constraint on interpretations of the B Deduction: each of $\$ \$ 15-19$ and $\$ \$ 22-26$ must make a distinct contribution towards the argument, and not simply restate the results of the other in the manner of the distinct expositions of the A Deduction. ${ }^{8}$ But respecting this constraint has not proved easy. Indeed Guyer has gone so far as to suggest that it is 'deeply problematic whether Kant should have suggested that there are two stages to the deduction' at all (Guyer 1992, p.160, fn.32). After all, at the end of the first part of the proof Kant takes himself to have shown that all sensible intuition stands under the categories. So what remains to be done in the second part?

An immediate source of puzzlement is the fact that Kant appears to take the second part of the proof to be narrower in scope than the first. ${ }^{9}$ As the title of section 20 makes clear, the first part of the proof has shown that all sensible intuitions stand under the categories, whereas in section 26, Kant's concern is with the way in which the empirical intuition is given in sensibility' (B143), i.e., with sensible intuition as it is given to us in space and time. This suggests that $\$ \$ 15-19$ prove that the categories have objective validity for all sensible intuition, whilst $\$ \$ 22-26$ prove further that they do so specifically for human sensible intuition. But such an interpretation makes the second part of the proof redundant. For if the categories apply to all sensible intuition, then a fortiori they apply to all human sensible intuition as anything that is true of the genus is a fortiori true of the species.

Henry Allison has suggested that redundancy can be avoided by appealing to a distinction between the conditions necessary for the thought of empirical objects and those necessary for the perception of such objects. ${ }^{10}$ For Allison, $\$ \$ 15-21$ comprise an argument for the claim that the categories function as conditions on the possibility of any thought of empirical objects, whilst $\$ \$ 22-26$ argue for the claim that they are also conditions on the possibility of perceiving such objects. Such an interpretation avoids redundancy because it does not follow from the fact that the categories are necessary for thinking about empirical objects that

\footnotetext{
8 (Henrich 1969)

9 This tells against any interpretation which takes the second part of the proof to involve the lifting of a restriction that was in place for the first part. (Henrich 1969) is often read this way, e.g., by (Allison 2004, pp.160-2), though it is not clear that such an interpretation best fits his intentions. ${ }^{10}$ (Allison 2004: pp.159-163, p.185).
} 
they are also necessary for perceiving them. Moreover, Allison argues that $\$ \$ 22-26$ are needed to complete the deduction, since Kant's aim is to 'establish the applicability of the categories to whatever is given under the conditions of human sensibility' (Allison 2004: p.162), and it is only by showing, further, that the categories are necessary for the perception of empirical objects that this aim can be fulfilled.

Allison's interpretation is important to the extent that it draws attention to the shift in Kant's argument from a focus on the categories as intellectual conditions of empirical representation to the relation they bear to the forms of human sensible intuition. However as stated it remains vulnerable to a version of Van Cleve's objection. For Allison, the shift between the two parts of the deduction involves a change in the domain over which application of the categories is deemed necessary, from that of thought of empirical objects to our perception of them. But the most this can establish is that the applicability of the categories is necessary for the perception of empirical objects; that we must apply the categories in order to perceive empirical objects. But, as Van Cleve has pointed out, this falls short of showing that they must so apply. Although it avoids redundancy, Allison's interpretation of Kant's argument fails to establish that the categories are instantiated by the objects of experience and, as such, we would do better to look elsewhere for an account of the two-part structure. ${ }^{11}$

How, then, do we avoid the threat of redundancy? Consider the following passage in which Kant summarises the results of the first part of the B Deduction, before setting out the aims of the second:

...in the transcendental deduction, however, their [the a priori categories] possibility as a priori cognitions of objects of an intuition in general was exhibited $(\$ \$ 20,21)$. Now the possibility of cognising $a$ priori through categories whatever objects may come before our sense, not as far as the form of their intuition but rather as far as the laws of their combination are concerned... is to be explained. (B160)

Kant stresses in this passage that, whereas the first part of the proof has been concerned with 'intuition in general', the second part will be focused

${ }^{11}$ Note that Allison's phrasing is susceptible to the ambiguities identified by Van Cleve (p.89). Kant's aim is to 'establish the applicability of the categories to whatever is given under the conditions of human sensibility' (Allison 2004: p.162), but to establish that the categories are applicable is not to establish that they are rightly or properly so. 
on objects as they come before our senses - that is, in so far as they stand in space and time. The proof moves from intuition in general to the way in which objects are given to us. Does this make the second part of the proof redundant?

The threat of redundancy appears genuine so long as we read the first part of Kant's proof as concerned with application of the categories to all sensible intuition, and the second as concerned with application of the categories to human sensible intuition, since the latter is a proper subset of the former. But this reading distorts Kant's focus. It is not the application of the categories to human sensible intuition which is under consideration, but the way in which objects may come before our senses, that is, the forms of human sensible intuition themselves. The result is a movement away from the categories as intellectual conditions on the representation of objects to the sensible conditions under which such objects are presented. As Béatrice Longuenesse puts it, Kant's concern is 'neither the relation of the categories to sensible intuition in general, nor even their relation to our (spatiotemporal) sensible intuition, but space and time themselves' (Longuenesse 1998: p.213).

This focus on the way in which objects are given to us is made explicit in Kant's first presentation of the two part structure in section 21:

...since the categories arise independently from sensibility merely in the understanding, I must abstract from the way in which the manifold for an empirical intuition is given, in order to attend only to the unity that is added to the intuition through the understanding by means of the category. In the sequel $(\$ 26)$ it will be shown from the way in which the empirical intuition is given in sensibility that its unity can be none other than the one the category prescribes to the manifold of a given intuition in general according to the preceding $\$ 20$; thus by the explanation of it's a priori validity in regard to all objects of our sense the aim of the deduction will first be fully attained. (B144-5)

The key sentence in this passage states that the sequel will show 'from the way intuition is given in sensibility that its unity can be none other than the one the category prescribes'. The claim here is that the second part of the B Deduction proof must show how space and time are so constituted that the unity of the manifold can be no other than that prescribed by the categories. The passage announces a move in section 26 away from consideration of the understanding as the faculty of judgement, to 
consideration of empirical intuition as it is given to us under the sensible conditions of space and time.

For Longuenesse, this shift in focus marks a reinterpretation of the results of the Transcendental Aesthetic in light of the first part of the Transcendental Deduction. Kant's aim, she says, is to 'radicalize his deductive procedure by reinterpreting... the manner in which things are given to us... The goal of the Transcendental Deduction of the Categories is "fully attained" only when it leads to a rereading of the Transcendental Aesthetic' (Longuenesse 1998: p.213). It is certainly true that the deduction is only fully attained once we have turned to the manner in which things are given to us, but talk of 'rereading' can give the impression that the second part of the Deduction is strictly inessential to the task of showing that the categories are instantiated by the objects of experience; that all that remains to be done is to consider how the concerns of $\$ \$ 15$ 19 bear on the Aesthetic's account of space and time. This conflicts with Kant's express commitment to the necessity of $\$ \$ 22-26$ for demonstrating the exemplification of the categories. Although the focus is the manner in which things are given to us, it is in the service of proving that the categories are instantiated by the objects of experience.

What role, then, does the second part of the deduction play? Kant's concern in these sections is with human sensible intuition and the way in which it makes the manifold available to the subject. But what would it be to show that 'from the way in which intuition is given in sensibility that its unity can be none other than the one the category prescribes'? To make good this claim would be to show that the way in which objects are given to us in space and time makes it the case that the manifold must be unified in accordance with the categories. That is, the second part of the B Deduction aims to show that it follows from the way in which appearances are given to us that those things given in space and time must be unified in accordance with the categories. Since the objects of experience are given to us in space and time, it follows that they must be unified in accordance with the categories. To show that the unity 'can be none other than the one the category prescribes' is to show that the categories must apply. ${ }^{12}$

12 A reviewer noted that this only follows given Kant's commitment to transcendental idealism. I say more about the role transcendental idealism plays in the argument in the next section. 
This is where Van Cleve's objection illuminates the two part structure of the B Deduction. For as set out above, the argument of the A Deduction (and B Deduction $\$ \$ 15-19$ ) is vulnerable precisely to the charge levelled at it by Van Cleve. As reconstructed, that argument went as follows: all representations are subject to the transcendental unity of apperception. This unity is synthetic. Such a synthetic unity requires an a priori synthesis of the manifold according to a priori rules. These rules are the categories. But Van Cleve's objection to this argument holds good: the most that follows from this argument is that in unifying the manifold I must apply the categories - something which is compatible with the claim that the categories do not apply to the objects of experience. Failure to show that the categories must apply is a failure to show that they are objectively valid.

This objection identifies a serious failing of the A Deduction - and correspondingly, of the first part of the B Deduction. To complete his proof of the objective validity of the categories Kant must show not only that we must make use of the categories in making judgements about objects of experience, but also that the categories do actually apply to those objects of experience. And this suggests the following interpretation of the two step procedure of the B Deduction: Kant moves from the claim that we must apply the categories to the claim that the categories must apply. With this distinction in mind, the above passages become clearer. Kant turns his attention to the way that intuition is given in sensibility in order to show that our sensible intuition, that is, spatio-temporal intuition, is constituted in such a way as to necessitate the unification of the manifold under the application of the categories. Hence the focus in section 26 on space and time themselves, for it is only by showing that space and time, as the sensible conditions of our intuition, are constituted so as to make instantiation of the categories necessary that Kant can complete his proof. The second part of the B Deduction makes good the deficiency identified by Van Cleve.

How does Kant support this move? On any interpretation the argument here is rather dense. The bulk of it takes place in section 26, with a reference to material expounded in section 24. In these passages Kant argues that space and time, as the forms of human sensible intuition, structure the manifold of appearance since such a manifold 'can only occur in accordance with this form' (B161). But space and time are represented by us not only as forms of sensible intuition, but also as intuitions themselves, and therefore as possessing a unity of the manifold of empirical 
intuition within them. This unity 'precedes all concepts, though to be sure it presupposes a synthesis, which does not belong to the senses but through which all concepts of space and time first become possible' (B161n.). This presupposed synthesis is one in which 'the understanding determines the sensibility' (B161n.). So the unity of space and time is to be explained with reference to the effect of the understanding upon sensibility itself.

Kant expands upon this in the footnote to section 26. He draws attention to the dual role played by space and time: as forms of intuition they present the manifold of intuition to the understanding, but as formal intuitions they 'give unity to the representation.' (B160n.). This unity precedes all concepts but derives from a transcendental synthesis of the imagination; a process defined in section 24 as 'an effect of the understanding on sensibility' (B152). ${ }^{13}$ So the unity of space and time is explained in terms of the synthetic activity of the understanding: space and time stand under the synthetic unity of apperception. ${ }^{14}$ And in so far as they are represented as unities they are themselves the product of the effect the understanding has upon sensibility. Hence Kant's claim that the unity of space and time 'has its seat in the understanding' (B162). ${ }^{15}$

These claims shed light on Kant's puzzling interjection at the end of section 15 where he says that the combination of a manifold presupposes a unity which cannot arise from the combination but rather makes the combination possible (B130-131). ${ }^{16}$ Kant introduces in this paragraph a unity of the manifold which 'precedes all concepts of combination a priori' and 'is not the former category of unity', but is instead a higher unity which grounds all combination. Guyer complains that this interjection 'obscures the intended relationship between the categories and the unity of apperception' and endangers the entire project of showing that the categories apply to the objects of experience (Guyer 1992, pp.149-150), but the previous discussion suggests an alternative explanation: the unity Kant refers to is the unity of space and time provided by the synthetic unity of apperception through its role in transcendental synthesis. And far

13 The footnote at B160 refers back explicitly to section 24 .

${ }^{14} \mathrm{Cf}$. the footnote in (B136): 'Space and time and all their parts are intuition... and consequently the unity of consciousness as synthetic and yet original, is to be found in them.' (B136n.)

15 (Longuenesse 1998, ch.8) discusses this move in detail. See also (Waxman 1991, chs.13).

${ }^{16}$ Longuenesse links the discussion of space and time in section 26 with Kant's comments at the end of section 15. See (Longuenesse 2000: pp.105-106). 
from endangering the project of the Transcendental Deduction, it plays a central role in the completion of Kant's proof.

How, then, does this relate to the role played by the second part of the deduction? Let us accept that the unity of sensibility presupposes a transcendental synthesis of the imagination in which the understanding affects sensibility in order to generate some aspect of our representations of space and time. Why should this assist with showing that the categories are exemplified in experience? A short answer would be possible if this synthesis itself took place according to the categories, for then appearances would accord with the categories simply in virtue of according to the formal intuitions of space and time: thus anything given in space and time would, of necessity, exemplify the categories. But Kant's insistence that transcendental synthesis 'precedes all concepts' marks this quick response unavailable, for although space and time involve an effect of the understanding upon sensibility, it is one which antedates any involvement of concepts including the categories.

How is it possible for there to be a function of the understanding which precedes all concepts when the understanding is introduced as the 'faculty for judging' (A69/B94), and judgement takes place according to concepts (A69/B94; A126) or in accordance with rules (A126ff.)? It is interesting to note in this context, Kant's characterisation of the understanding in the $\mathrm{B}$ Deduction as the capacity for apperception (B133-4n.); a capacity which he identifies as more fundamental than the categories (A401). The synthetic unity of apperception is 'the highest point to which one must affix all use of the understanding, even the whole of logic and, after it, transcendental philosophy; indeed this faculty is the understanding itself (B133-4n., my emphasis). It is in virtue of its characterisation as the capacity of apperception that the understanding can perform this role prior to the application of concepts. ${ }^{17}$

Thus although the transcendental synthesis which makes possible our representation of space and time does not itself involve the categories, it has its origin in the same source as the categorial synthesis which takes

\footnotetext{
${ }^{17}$ Kant also links the synthetic unity of apperception to the form of all judgements, e.g., in the title of $\$ 19$ : see also (A108-9, B136-7). For a reading which stresses Kant's claims about objective judgements, see (Henrich 1994), but note the criticism in (Ameriks 2003) that such a reading is inadequate precisely because it ignores the role played by the forms of intuition in Kant's argument (Ameriks 2003: p.93).
} 
place on the manifold of intuition given in space and time. And Kant's thought seems to be that because of this shared origin, appearances which are given in space and time thereby fall under the same synthetic unity of apperception which is responsible for synthesising the manifold of intuition in accordance with the categories. It is in virtue of standing under the same synthetic unity of apperception that the unity of appearances can be 'none other than that of the combination of the manifold' (B161), for it is one and the same understanding which undertakes both the transcendental synthesis necessary for the representation of space and time and the categorial synthesis of the manifold of intuition given in space and time. Anything given in space and time, in virtue of standing under the synthetic unity of apperception, must be unified in accordance with the rules by which the understanding generates a unity. And these rules are the categories. ${ }^{18}$

As I said, this argument is quite dense and raises as many questions as it answers. ${ }^{19}$ But the intention seems clear. Having shown that we must unify the manifold of intuition in accordance with the categories, Kant turns to the forms of human intuition in order to show that the manifold of intuition must be so unified. Space and time, represented as unities, are a result of the understanding's effect upon sensibility and stand under the synthetic unity of apperception. That which is presented in space and time is thereby presented in accordance with the understanding, and the only way it can be unified is by the understanding using the categories. It is not simply that we must apply the categories, as the first part of the proof has shown in relation to all sensible intuition. It is also that the manifold is such that the categories must apply to it. This second step is needed to secure the objective validity of the categories, and though more needs to be said to clarify the argument used in support, the general structure can be seen. The second step of the B Deduction is designed to take Kant from the claim that we must apply the categories to the claim that the categories must apply. Kant's argument is fit for purpose.

\footnotetext{
18 Note that the two forms of synthesis are complementary for even though appearances fall under the unity of apperception in virtue being given in space and time, they still need to be taken up and synthesised in accordance with the categories in order that experience be more than a mere 'rhapsody of perceptions' (A156/ B195).

${ }^{19}$ For discussion and commentary see (Allison 2000) and (Longuenesse 2000)
} 


\section{Transcendental Idealism}

My concern in this paper has been Van Cleve's suggestion that there is a structural problem with the Transcendental Deduction. According to Van Cleve, Kant's aim in the Deduction is to show that categories are instantiated in experience, but the most that his argument can show is that we must apply the categories when synthesising the manifold of intuition. This falls short of showing that the categories are instantiated, Van Cleve suggests, because our application of the categories to the manifold may not be true. I have suggested that once we attend to the two part structure of the B Deduction, this objection loses its force. For although the first part $(\$ \$ 15-19)$ is concerned only to show that we must apply the categories, the second (\$\$22-26) aims to show further that the categories must apply. So Van Cleve's structural objection is misplaced.

Nevertheless, given my suggestion that the A Deduction is structurally equivalent to the argument of $\$ \$ 15-19$ of the B Deduction, this might suggest that Van Cleve's objection has force against the first edition version of the Critique and that Kant's recognition of this lacuna occurs only in the second edition. I sympathise with the spirit of this claim, but in letter it is too simplistic. For if we now return to the A Deduction with the above discussion in mind, a number of troubling passages passed over in Van Cleve's exposition become clearer. I have in mind the passages right at the end of the A Deduction where Kant claims that 'we ourselves bring into the appearance that order and regularity in them that we call nature' (A125), and later that the 'understanding is... not merely a faculty for making rules... it is itself the legislation for nature, i.e., without understanding there would not be any nature at all' (A126).

It is tempting to think of these passages as allegorical, but the discussion of the second part of the B Deduction above suggests the following: the move to make the order and regularity depend on 'we ourselves' is an attempt to solve the problem of how to move from the conclusion that we must apply the categories to the conclusion that the categories must apply. The argument in section 26 held that the understanding itself makes intuition possible, through synthesis of the pure intuitions of space and time. We can read these passages as attempting to answer the same problem: how can we know that our intuitions are so constituted that they need be unified under the unity of apperception? We can know they are so constituted because the understanding itself makes them so. Granted these 
passages only make sense within the transcendental idealist framework where the empirical world is the world of appearances, but we can see the motivation for the transcendental idealist framework as an attempt to explain how we can be sure that the categories must be instantiated in experience. ${ }^{20}$

If this is correct, then Kant was aware of the distinction between showing that we must apply the categories and showing that the categories must apply in the A Deduction, and understood even then that more had to be done to ensure that the categories were objectively valid. But there are two important changes in the B Deduction. The first is methodological; the argument is broken up into two distinct and clear steps to demonstrate that such a transition is needed even after considerations about the unity of apperception have demonstrated that it is necessary for us to apply the categories. The second is more substantial: it is in the B Deduction that Kant connects the argument for the instantiation of the categories to the way in which empirical intuition is given to us.

And this has important implications for the role that transcendental idealism plays in the B Deduction. ${ }^{21}$ In the A Deduction, transcendental idealism allows Kant to avoid Van Cleve's objection through a general distinction between the world of appearances and the world as it is in itself and the further claim that the world of appearances depends for its nature on we ourselves. But in the B Deduction, transcendental idealism enters as a specific thesis about the a priori nature of space and time and the role of the understanding in enabling sensibility to present intuitions to the subject. It is because space and time are pure intuitions whose representation is determined in part by the effect of the understanding upon sensibility that objects given in space and time fall under the synthetic unity of apperception and are thus subject to the categories. Transcendental idealism enables Kant to complete the deduction not because of a general distinction between appearances and things-inthemselves but through a specific focus on the a priori nature of spatiotemporal intuition. ${ }^{22}$

20 (Cassam 1987) provides a similar reading of these passages.

${ }^{21} \mathrm{My}$ thanks to a reviewer for suggesting this line of thought.

${ }^{22}$ Karl Ameriks has argued forcefully that Kant's arguments for transcendental idealism depend specifically on his views about the nature of space and time. See his discussion of long and short arguments to idealism in (Ameriks 2000, pp.163-186). 
The result is that transcendental idealism enters the $\mathrm{B}$ version of the Deduction in a much more subtle and interesting way than it does the A. Rather than appealing to very general claims about the understanding acting as the 'legislator for nature' (A126) or as the 'source of the laws of nature' (A127), Kant focuses instead on the specific way in which space and time, as formal intuitions, owe their unity to the effect of the understanding upon sensibility. It is the understanding which makes it possible for us to be presented with appearances through its role in generating the unities of space and time. Transcendental idealism plays a central role in both versions of the Deduction, but it is only in the B edition that it is enters as a substantive claim about the manner in which things are given to us in sensibility.

With regards to this point, of possible interest is a note inserted in Kant's copy of the first edition at the end of the passage in the A Deduction quoted above:

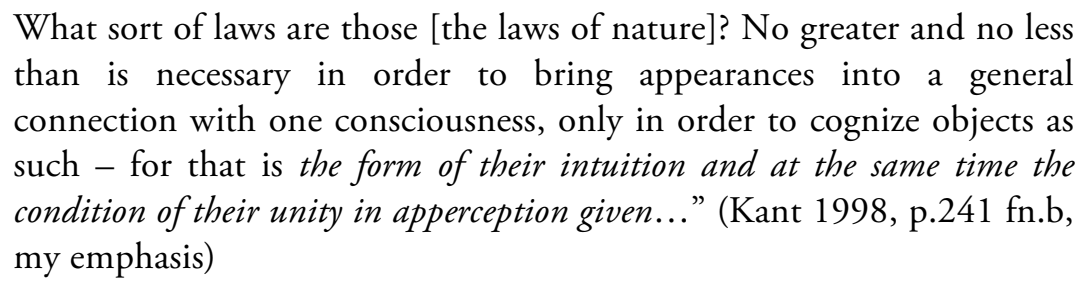

It is not too great a leap of the imagination to see the final sentence of this note as indicating a change in the approach to the problem of how we can know that intuitions are such as to require unification under synthesis, from emphasising the claim that we literally make the laws of nature to the thought that it is the forms of intuition, space and time, that serve as the condition of their unity and therefore the necessity of their being unified by the understanding. The B Deduction makes this move explicit, and in doing so serves to acquit Kant of Van Cleve's charge. ${ }^{23}$

\footnotetext{
${ }^{23}$ My thanks to two anonymous reviewers whose comments have greatly improved this paper.
} 


\section{References}

Allison, H. (2000). 'Where Have all the Categories Gone? Reflections on Longuenesse's Reading of Kant's Transcendental Deduction', Inquiry 43: 67-80.

Allison, H. (2004). Kant's Transcendental Idealism: An Interpretation and Defense, Revised and Enlarged Edition. London, Yale University Press.

Ameriks, K. (2000). Kant and the Fate of Autonomy: Problems in the Appropriation of the Critical Philosophy. Cambridge, Cambridge University Press.

Ameriks, K. (2003). 'Recent Work on Kant's Theoretical Philosophy', reprinted in his Interpreting Kant's Critiques. Oxford, Oxford University Press: 67-97.

Cassam, Q. (1987). 'Transcendental Arguments, Transcendental Synthesis and Transcendental Idealism', Philosophical Quarterly 37: 355-378.

Guyer, P. (1992). 'The Transcendental Deduction of the Categories', in P. Guyer (ed.) The Cambridge Companion to Kant. Cambridge, Cambridge University Press.

Henrich, D. (1969). 'The Proof-Structure of Kant's Transcendental Deduction.' Review of Metaphysics 22: 640-659.

Henrich, D. (1994). 'Identity and Objectivity: An Inquiry into Kant's Transcendental Deduction', in his The Unity of Reason: essays on Kant's Philosophy. London, Harvard University Press: 123-210.

Kant, I. (1998). Critique of Pure Reason, tr. P. Guyer and A. Wood. Cambridge, Cambridge University Press.

Longuenesse, B. (1998). Kant and the Capacity to Judge. Princeton, Princeton University Press.

Longuenesses, B. (2000). 'Kant's Categories and the Capacity to Judge: Responses to Henry Allison and Sally Sedgwick', Inquiry 43: 91-110.

Van Cleve, J. (1999). Problems from Kant. Oxford, Oxford University Press.

Waxman, W. (1991). Kant's Model of the Mind. Oxford, Oxford University Press. 